\title{
A compreensão sistêmica e o pensamento do design para o desenvolvimento de produtos para a cultura slow food e práticas colaborativas
}

Moreira-Victoria, Isabel Cristina ${ }^{\mathrm{a}}$; Figueiredo-Ourives-de, Atillio Bolivar ${ }^{\mathrm{b}}$; OurivesAssunção, Eliete Auxiliadorac ${ }^{c}$;igueiredo-Gonçalves-de, Luiz Fernando ${ }^{\text {d }}$; Ribeiro-deFreitas-Rabelo, Giovana ${ }^{\mathrm{e}}$ \& Castro-Gómez, Francisco ${ }^{\mathrm{f}}$

${ }^{a}$ Núcleo de Abordagem Sistêmica do Design - Universidade Federal de Santa Catarina, Brasil isabel.mvictoria@gmail.com,

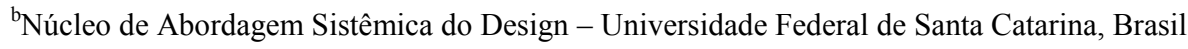
gastronomia.cosine@gmail.com,

${ }^{\mathrm{c}}$ Núcleo de Abordagem Sistêmica do Design - Universidade Federal de Santa Catarina, Brasil elieteourives@gmail.com,

${ }^{\mathrm{d} N u ́ c l e o ~ d e ~ A b o r d a g e m ~ S i s t e ̂ m i c a ~ d o ~ D e s i g n ~-~ U n i v e r s i d a d e ~ F e d e r a l ~ d e ~ S a n t a ~ C a t a r i n a, ~ B r a s i l, ~}$ 1ff@cce.ufsc.br,

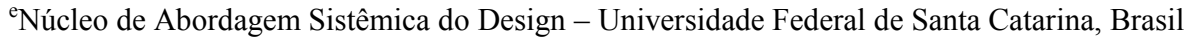
giovanafrr@gmail.com,

${ }^{\mathrm{f}}$ Núcleo de Abordagem Sistêmica do Design - Universidade Federal de Santa Catarina, Brasil francisco.gomez.castro1@gmail.com.

\section{Resumo}

A sociedade atual vive em um contexto tumultuoso, sendo comumas pessoas viverem mais estressadas, se alimentando mal e convivendo cada vez menos com as pessoas, perdendo oportunidades de fazer e manter relacionamentos pessoais. Como este estilo de vida está saturado, gerando problemas de saúde aos indivíduos, existem diversos estudos que comprovam a tendência de que as pessoas buscarão um melhor aproveitamento do seu tempo, com um maior contato com a natureza, dando valor ao seu próprio bem-estar, prestando mais atenção no que consome e em como consome, assim como a valorização do prazer de estar em um meio social. Nesse contexto, o objetivo deste trabalho é contribuir por meio da visão sistêmica e do design, para o incentivo e a prática da filosofia Slow Food, e dessa forma, promover a preocupação com uma saudável forma de alimentação e a ação colaborativa entre as pessoas, em que um individuo possa cooperar com o outro, resgatando o convívio e socialização. Assim, pretende-se atuar em pequenas unidades urbanas externas, como prédios, condomínios, praças e avenidas 
A compreensão sistêmica e o pensamento do design para o desenvolvimento de produtos para a cultura slow food e práticas colaborativas

com intuito de criação de um artefato que motive a prática dessa filosofia, assim como impulsione também as práticas colaborativas nestes locais, buscando a integração social e desenvolvimento econômico e ambiental, atendendo os princípios da sustentabilidade e o desenvolvimento local. $O$ método de pesquisa usado é descritivo, em que se observou e analisou as situações e relações dos indivíduos, tanto de forma individual quanto as relações em sociedade. Os instrumentos escolhidos para coleta de dados foram o questionário, entrevistas e observações abertas, feitas informalmente ao decorrer das entrevistas. Neste trabalho integrou-se dois métodos de projeto, a ferramenta HCD/IDEO (Human Centered Design - Design Centrado no Ser Humano), usado como base, com técnicas para o entendimento dos desejos e necessidades da comunidade estudada e o Guia de projeto NASDesign/UFSC (Núcleo de Abordagem Sistêmica do Design/Universidade Federal de Santa Catarina), dividido em três fases: Sentir, Agir e Realizar, como complementação. Ao final, conclui-se que o modelo físico do produto proposto atende uma lista de requisitos divididos em três grande grupo: requisitos de produto, referentes à forma, materiais e texturas do objeto; requisitos do usuário, referente a necessidade entendida a partir do tipo de ambiente em que o produto está, e de como ele está sendo usado e aos requisitos do contexto de uso, que consiste nas necessidades do usuário observado durante a pesquisa.

Palavras-chave: design de produto, slow food, sustentabilidade.

\begin{abstract}
The current society lives in a tumultuous context, being common people live more stressed, feeding badly and living less and less with people, losing opportunities to make and maintain personal relationships. As this lifestyle is saturated, generating health problems for individuals, there are several studies that prove the tendency for people to seek better use of their time, greater contact with nature, giving value to their own well-being, paying more attention to what is consumed and how it is consumed, as well as valuing the pleasure of being in a social environment. In this context, the objective of this work is to contribute through the systemic vision and the design, to the incentive and practice of the Slow Food philosophy, and in this way, to promote the concern with a healthy form of food and the collaborative action among the people, in which one individual can cooperate with the other, rescuing the social and socialization. Thus, it is
\end{abstract}


intended to work in small external urban units, such as buildings, condominiums, squares and avenues with the intention of creating an artifact that motivates the practice of this philosophy, as well as boosting the collaborative practices in these places, seeking social integration and development economic and environmental, according to the principles of sustainability and local development. The research method used is descriptive, in which the situations and relations of individuals, both individually and in society, were observed and analyzed. The instruments chosen for data collection were the questionnaire, interviews and open observations, made informally during the interviews. In this work we integrate two methods of design, the HCD / IDEO (Human Centered Design) tool, used as a base, with techniques to understand the desires and needs of the studied community and the NASDesign / UFSC (Center for Systemic Approach to Design / Federal University of Santa Catarina), divided into three phases: Feel, Act and Realize, as a complement. At the end, it is concluded that the physical model of the proposed product meets a list of requirements divided into three major groups: product requirements, referring to the shape, materials and textures of the object; user requirements, referring to the need understood from the type of environment in which the product is, and how it is being used, and the requirements of the use context, which consists of the user needs observed during the search.

Keywords: product design, slow food, sustainability.

\section{Introdução}

A sociedade atual vive em um ritmo extremamente acelerado. As pessoas dormem pouco, vivem preocupadas com suas obrigações profissionais, se alimentam com pressa, estão sempre atentas aos mais variados meios tecnólogicos (tablets, celulares, computadores...) e diminuíram consideravelmente o contato físico com as outras pessoas, procurando envolver-se apenas com seus próprios problemas e dispensando ajuda de outros indivíduos. Todas essas características são nocivas a saúde mental e física das pessoas, prejudicando o próprio corpo e os relacionamentos pessoais da população. 
Alguns movimentos incentivam as pessoas a desacelerar o ritmo, propondo uma reavaliação de prioridades e do uso do tempo. Um desses movimentos é o Slow Food, que surgiu para contrapor o já disseminado Fast food, se opondo a padronização do alimento. $\mathrm{O}$ movimento propõe uma melhor qualidade na alimentação das pessoas incentivando o consumo de alimentos que não levem tantos produtos químicos em seus componentes, além de incentivar o contato com o preparo dos alimentos e a calma para realizar a refeição, observando texturas, cheiros e sabores.

Característica também comum na sociedade atual é a individualidade e a falta de habilidade em utilizar o tempo a seu favor, utilizando-o apenas para obrigações. Alguns povos espalhados pelo mundo possuem enraizados em suas culturas um equilíbrio no uso do tempo, para o povo de Kelantese, na Malásia "a pressa é considerada uma falta de ética por reduzir o tempo disponível para visitar e socializar com amigos, parentes e vizinhos" (Thackara, 2008). A partir do já mencionado Slow Food e de comunidades como a de Kelantese, outros movimentos foram criados. Organizações de pequenos grupos que buscam levar uma vida mais leve, tentando encontrar o equilíbrio entre o estresse ao qual as pessoas já estão habituadas e a tranquilidade a qual as pessoas buscam.

Estudos de tendências feitos pela Fundação Telefônica Vivo para os próximos 15 anos, apresentados no final do ano de 2015, revelam que nos próximos anos as pessoas tendem a ter uma preocupação maior com seu bem-estar físico e psicológico, também haverá uma maior responsabilidade social e ambiental, em que o indivíduo se inclina às necessidades de sua comunidade e pensa nas gerações futuras, buscando formas de consumo menos impactantes ao meio-ambiente.

Pensando nesse contexto, este projeto busca contribuir por meio do design a ação colaborativa entre as pessoas, em que um indivíduo possa cooperar com o outro, resgatando o convívio e socialização. Em comunhão com esse objetivo busca-se o incentivo a prática da filosofia Slow Food, promovendo a preocupação com uma saudável forma de alimentação. Para abordar estes temas será utilizada a vertente do design que se dedica a criação de produtos. O produto em questão será um mobiliário urbano.

\section{Metodologia}

Para a elaboração desse projeto foram integrados dois métodos projetuais: a ferramenta HCD/IDEO e Guia Projetual NAS-DESIGN. Ao longo do projeto serão utilizadas ferramentas do Guia Projetual NAS-DESIGN e do kit de ferramentas HCD.

O kit de ferramentas HCD (figura 1) começa com um desafio estratégico específico e continua em três fases: Ouvir, Criar e Implementar. "A razão pela qual esse processo é 
chamado de "Centrado no Ser Humano" é que ele começa pelas pessoas para as quais estejamos criando a solução" (HCD, 2010, p.5). A primeira fase é "Ouvir" e fundamenta-se em coletar histórias das pessoas que formam o público do projeto, sendo composta por observações e pesquisas de campo. A segunda fase desse método é "Criar", nela acontece a busca por oportunidades e soluções do que foi ouvido e observado do público. A terceira e última fase é "Implementar", ela marca o início da implementação de soluções.

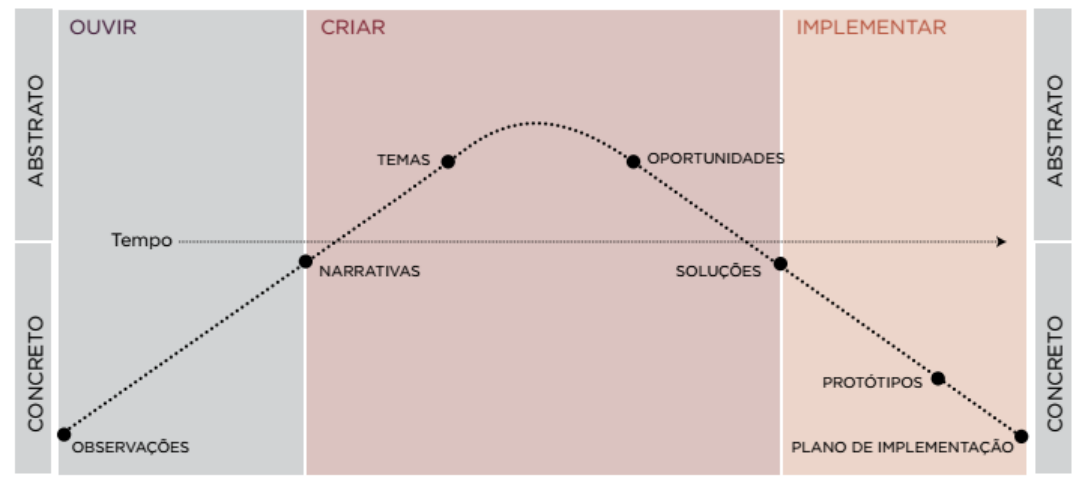

Fig. 1 Processo HCD. (HCD, 2010)

O Guia Projetual NAS DESIGN foi desenvolvido pelo Núcleo de Abordagem Sistêmica do Design (NAS Design), que é um laboratório acadêmico pertencente ao Departamento de Expressão Gráfica, localizado no Centro de Comunicação e Expressão da Universidade Federal de Santa Catarina em Florianópolis. O método consiste em "uma abordagem sistêmica, onde o design é entendido como um processo holístico, e, dessa forma, o foco é deslocado do produto final para o sistema produtivo e suas complexas interações" (AROS, 2016, p. 46).

Esse método consiste em três fases: "Sentir", "Agir" e "Realizar" (Figura 2). A fase "Sentir" é o primeiro contato com a comunidade, em que define-se a problematização e ocorrem as primeiras conversas e experiências com a comunidade estudada, coletando informações e conteúdo para o projeto. A segunda fase é "Agir", nela busca-se desenvolver soluções tangíveis, com o apoio e participação do público-alvo. A terceira fase é "Realizar", e fundamenta-se em implementar o produto final e dar suporte à comunidade se necessário. Assim como explicado na Figura 3. 


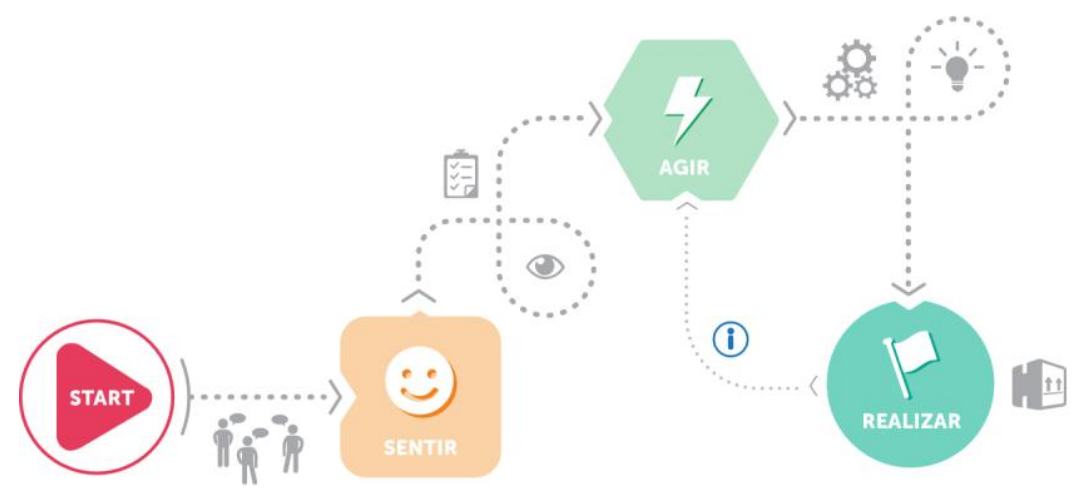

Fig. 2 Etapas do Guia Projetual (NAS DESIGN, 2016)

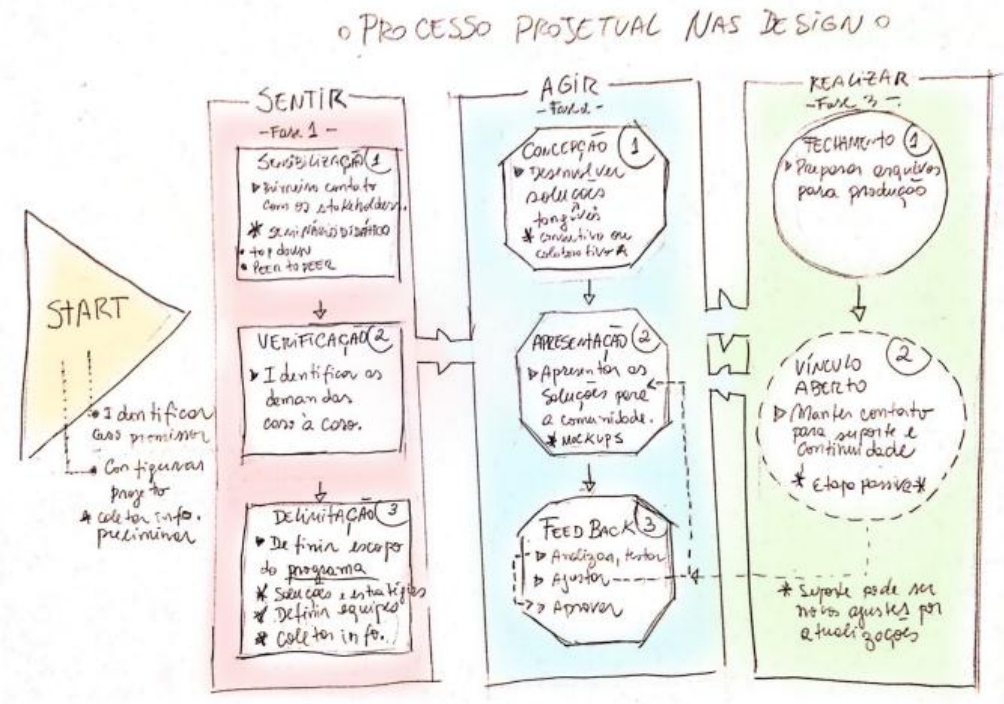

Fig. 3 Detalhamento dos processos do Guia Projetual NAS DESIGN (Aros, 2016)

\section{Design e sustentabilidade}

A sociedade está em um momento de transição de costumes e entendimentos sobre o mundo e suas limitações. Os designers caminham junto com essa mudança social tendo, agora, noção que as decisões de design "moldam os processos por trás dos produtos que utilizamos, os materiais e a energia necessária para produzi-los, o modo como operamos no dia-a-dia e o que acontece com eles quando perdem a utilidade" (Thackara, 2008 p.24). 
Sendo assim, designers passaram a ter uma preocupação socioambiental muito mais elevada, buscando inserir o conceito de desenvolvimento sustentável em seus projetos.

"A introdução do conceito de desenvolvimento sustentável como elemento de ordem na concepção de novos produtos trouxe aos projetistas a consciência de seu papel em grande cadeia de intervenções, diretas e indiretas, sobre o meio ambiente". (Barbosa, 2009).

Barbosa (2009) ainda define princípios (e objetivos) para o desenvolvimento de produtos considerando as questões ambientais:
a) proteção aos recursos naturais e eficiência energética
b) atenuação de emissões e produtos poluentes
c) política social e ambiental das corporações
d) reciclagem e ciclo de vida
e) facilidade de conserto e atualização tecnológica
f) estética e vida longa
g) multiuso

Manzini (2008) reforça a necessidade de diminuir o consumo de recursos ambientais e de regenerar o ambiente físico e social, lembrando que esse processo de mudança para a sustentabilidade deve acontecer como resultado de uma escolha positiva, e não como reação a eventos desastrosos ou imposições autoritárias. Em síntese, “deve basear-se em uma transformação capaz de ser entendida por aqueles que a vivem como uma melhoria nas condições de vida (seja individual ou coletiva)" (Manzini, 2008, p.27). Para o autor a orientação de inovação rumo à sustentabilidade para designers deve recair na sua capacidade de orientar às próprias atividades, definindo objetivos que combinem suas próprias necessidades e exigências com os critérios da sustentabilidade que estão gradualmente vindo à tona. Sendo o mesmo também válido para empresas e cidadãos comuns em suas comunidades. Ou seja, novas (e sustentáveis) soluções devem ser concebidas e desenvolvidas (Mont, 2002).

O sentido dessas afirmações, segundo Manzini, podem ser entendidos "se considerarmos brevemente os passos a serem realizados no projeto (design) de uma nova solução" (Manzini, 2008). De forma simplificada, Manzini (2008) afirma que os passos são:

- Mudar a perspectiva - mudar o foco de interesses das coisas para os resultados, focalizando o processo de projeto nas atividades a serem realizadas. 
- Imaginar soluções alternativas - projetar diferentes combinações possíveis de produtos ou serviços de forma que esses resultados possam ser obtidos.

- Avaliar e comparar várias soluções alternativas - adotar um conjunto apropriado de critérios afim de julgar a efetiva convivência econômica, social e ambiental das alternativas identificadas.

- Desenvolver as soluções mais adequadas - projetar um processo que contenha dois movimentos: alavancar convergência entre empresas e os atores sociais envolvidos na realização da solução escolhida e conectá-los aos produtos, serviços e conhecimento que irão compor a solução (MANZINI, 2008).

Em reportagem da Revista Guia Exame apesar de que a intenção seja buscar novas soluções é afirmado que ser sustentável é pensar e agir com olhos no futuro. Mesmo que isso, em determinados momentos, signifique ganhar menos no presente. "Isso nada tem a ver com o fim do capitalismo. Ao contrário, é a senha para a sua sobrevivência como o melhor sistema econômico criado até hoje." (Revista Guia Exame, Sustentabilidade/out.2008, p.8).

Para Thackara (2008), o design consciente deve entregar valor para as pessoas, priorizando o ser humano. Além de pensar na consequência das suas decisões de projeto, buscando promover sistemas naturais e culturais da sociedade, lidando com esas questões como valores positivos e não obstáculos.

Se os designers não tinham noção de sua importância ambiental, econômica e social perante a produção e concepção de produtos, agora existe o conhecimento. Dessa forma a profissão pode ter contribuído para impactos ambientais, algumas vezes por indiferença e outras por desconhecimento, mas atualmente é sabido que um número enorme de designers trabalha arduamente para criação de produtos e serviços menos prejudiciais à biosfera. Partindo dessa ideia Thackara (2008) afirma que designers estão evoluindo de criadores de objetos para capacitadores de mudança.

\section{Slow food}

A expressão Slow Food é de origem inglesa e significa "comida lenta", o movimento surgiu para se opor a padronização do alimento no mundo, conhecido como Fast food (comida rápida em tradução literal).

O movimento foi fundado em 1986 por Carlo Petrini na cidade de Bra (Itália) e, em 1989 tornou-se uma associação sem fins lucrativos. Atinge mais de 100 mil membros, com apoiadores em mais de 150 países e escritórios em 7: Itália, Reino Unido, Japão, Estados Unidos, França, Alemanha e Suíça. 
Os alimentos que ingerimos e as coisas a nossa volta possuem relação direta, seja na paisagem, nos aspectos culturais ou na biodiversidade da terra. O Slow Food é um movimento gastronômico que não ignora esse vínculo, além disso busca melhorar a qualidade da alimentação e valorizar a necessidade do tempo que precisamos para fazer as refeições e, assim, poder apreciar e saborear os alimentos, tornando o cotidiano mais prazeroso. O movimento preza por um alimento bom, justo e limpo: o alimento deve ter sabor bom; os produtores devem receber o justo pelo seu trabalho; o alimento deve ser cultivado de maneira que não prejudique a saúde das pessoas, o meio ambiente ou os animais.

O Slow Food defende o alimento de qualidade, assim como o prazer de participar das etapas de preparação do alimento, utilizando produtos artesanais e respeitando o meio ambiente e os produtores. O movimento opõe-se à tendência da padronização dos alimentos e defende que os consumidores sejam bem informados, tornando-se assim co-produtores (pois tendo informação e apoiando verdadeiramente os produtores nos tornamos parceiros dos produtores, e por consequência co-produtores). Segundo Zuini, o movimento é definido por "uma combinação dos conceitos de sustentabilidade com comportamento - deixar a ansiedade e os compromissos para depois e realmente ter prazer na refeição" (Zuini, 2011).

O movimento caracteriza-se como marca por meio de um caracol (Figura 4), escolhido para representar o Slow Food pois se movimenta lentamente e se alimenta também calmamente durante seu ciclo de vida.

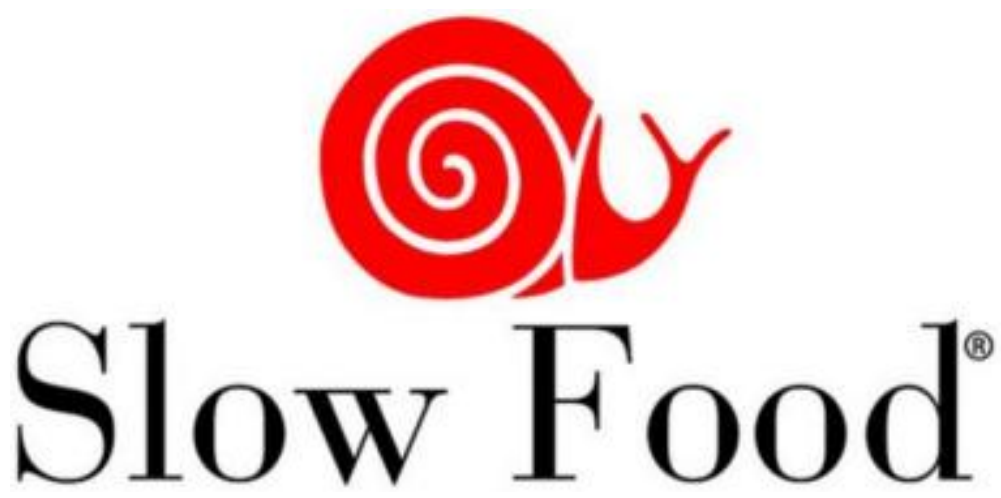

Fig. 4 Logotipo do Movimento (Slow Food, 2013)

A divulgação e, consequentemente, a quantidade cada vez maior de adeptos ao Slow Food está fazendo com que as pessoas diminuam também o ritmo no dia a dia, dando mais 
atenção às vivências e aos saberes artesanais (Capello, 2008). Essa é uma tentativa de desacelerar o ritmo do cotidiano para se reconectar a si mesmo, ao meio ambiente, às pessoas e ao lugar em que se vive (Capello, 2008).

\section{Design para inovação social}

Em sua essência o design busca promover o bem-estar das pessoas, por meio de suas variadas vertentes. No entanto, segundo Manzini (2008), desde o desabrochar da sociedade industrial - que possibilitou o desenvolvimento de ciência e tecnologia mutualmente vivemos em um bem-estar baseado no consumo de produtos, em que bem-estar significa a obtenção de mais produtos. Entretanto "mais produtos" significa um maior consumo de recursos naturais, logo o aumento de bem-estar está diretamente ligado ao consumo de recursos naturais. Esses recursos naturais não são recolocados na natureza, não gerando nem renovação nem preservação.

A crise econômica exigiu dos países mais maduros industrialmente uma reconsideração sobre esse modelo de bem-estar, buscando formas de viver melhor por meio da diminuição de consumo. Os países em situação econômica oposta, que estão em plena ascensão, as pessoas também estão sofrendo uma mudança socioeconômica e mudando o conceito de bem-estar (ManzinI, 2015).

"Dê um peixe a um homem e o alimentará por um dia. Ensine-o a pescar e o alimentará por toda sua vida" (Lao Tzu, 400 a.C.). Esse antigo ditado mostra duas diferentes alternativas para o mesmo objetivo, no caso a alimentação. Entretanto o ditado mostra como a sociedade se acostumou ao bem-estar baseado no consumo: se está com fome busque um fast food ou algum alimento enlatado. Essa ideia teve início a partir da produção em massa dos bens de consumo, a sociedade passou a ter um complexo sistema de produção de produtos e serviços para atende-la, afim de minimizar o envolvimento pessoal em qualquer serviço. Entretanto, segundo Manzini (2008), os seres humanos podem tender ao prazer em serem servidos, mas podem também comportar-se de modo completamente oposto, sendo possível na natureza humana tanto o caráter passivo como ser ativo e participativo. Os seres humanos são contraditórios, e a partir deste ponto que nasce a proposta de um novo tipo de bem-estar, o bem-estar ativo. Esse tipo de bem-estar traz "a condição na qual somos ativos e cuidamos de nós mesmos, da nossa família, da vizinhança e do ambiente, pois gostamos deles" (Manzini, 2008 p.55).

A inovação social busca justamente que a sociedade não seja apenas parte do problema, mas seja também parte da solução, ajudando a criar seu próprio bem-estar. A inovação social pode ser conceituada como "mudanças no modo como indivíduos ou comunidades agem para resolver seus problemas ou criar novas oportunidades. ” (Manzini, 2008 p.62). Para o autor, a união desses indivíduos gera as chamadas "comunidades criativas", sendo 
pessoas que trabalham de forma colaborativa e voluntária para resolução de problemas do dia-a-dia da comunidade, gerando hábitos que podem beneficiar a comunidade de forma econômica e social, além do benefício ambiental que essas comunidades podem gerar, contribuindo para a sustentabilidade.

Para Manzini (2015), tratando-se de inovação social não existe um estereótipo dos participantes, então a solução final entre o designer e o usuário torna-se mais nebulosa. Dado este fato, para favorecer a inovação social os designers devem, por meio de ferramentas e métodos projetuais, auxiliar essas comunidades incentivando suas iniciativas. "Uma visão cultural alternativa é vital para moldar as nossas expectativas e impulsionar a mudança transformadora" (Thackara, 2008 p.51). O autor complementa afirmando que visões compartilhadas são essenciais para dar impulso à inovação. Então o designer deve auxiliar "conversações sociais sobre o que fazer e como fazer" (Manzini, 2014 p.63), criando um processo de co-design com as pessoas em prol de uma mudança social.

É necessário então que designers criem condições favoráveis ao diálogo para que as pessoas possam expressar sua criatividade, organizando as informações por meio do seu conhecimento para que as comunidades possam se desenvolver de forma colaborativa e participativa, em que todos se sintam responsáveis pelo seu próprio bem-estar, assim como o da comunidade e do meio ambiente.

\subsection{Comunidades criativas}

Comunidades Criativas são inspiradas em iniciativas espontâneas, de pequenos ou grandes grupos de pessoas que desenvolvem trabalhos cooperativos, de uma maneira não convencional, para resolver problemas do dia a dia. Trata-se de uma proposta de um caminho sustentável para o século XXI (Montenegro, 2011). Para Manzini (2008) a sociedade contemporânea e toda sua complexidade pode ser vista como um laboratório de ideias para a vida cotidiana, onde o modo de viver e de resolver problemas são desdobrados e recriados, criando novas oportunidades. Para o autor "Existem muitos casos em que essa criatividade socialmente difusa se expressa no design de atividades que podemos denominar "colaborativas"." (Manzini, 2008, p.62). Como forma geral, as Comunidades Criativas sempre representam mudanças no seu contexto, pois desafiam a maneira tradicional de fazer, introduzindo novos modos de desempenho, diferente e intrinsecamente mais sustentáveis.

A ideia de que as pessoas resolvam os problemas sociais e ambientais de forma colaborativa, criando novas oportunidades e gerando respostas inéditas pode ser um forte passo rumo a sustentabilidade. Em que a sociedade, de forma conjunta, repara impactos sociais e ambientais, criando melhores cenários futuros.

Manzini (2008), destaca três características em comum em qualquer comunidade criativa: 
a. Pessoas que, de forma colaborativa, gerenciam e criam soluções inovadoras, usando a criatividade para quebrar modelos dominantes de pensar e agir, criando novos modos de vida.

b. As comunidades criativas nascem a partir de problemas da vida cotidiana contemporânea.

c. Resultam de uma combinação de demandas e oportunidades. Em que demandas são os problemas da vida cotidiana e oportunidades são combinações de três elementos: a existência ou memória de tradições; a possibilidade de usar produtos, serviços e infraestruturas; condições sociais e políticas capazes de aceitar o desenvolvimento de uma criatividade difusa.

Em síntese, pode-se dizer que as Comunidades Criativas são grupos de pessoas dispostas a agir colaborativamente, buscando soluções revolucionárias sem esperar que essas mudanças partam de um novo sistema econômico ou social. Essas pessoas dão um novo significado ao que já existe, aprimorando elementos para que eles se adaptem e resolvam questões da sociedade, criando elas mesmas, novos modos de resolução de problemas da vida cotidiana.

\section{Desenvolvimento}

\subsection{Ouvir+Sentir $=$ Primeira etapa}

$\mathrm{Na}$ primeira etapa do projeto foram unidas a primeira etapa de HCD e do Guia projetual NAS DESIGN. Nessa etapa foram realizados os levantamentos iniciais, feitos por meio de questionários, entrevistas e observação.

O questionário é um procedimento adotado para mapeamento e análise de dados econômicos, sociais e demográficos da população. Para que esse levantamento fosse realizado criou-se uma série de perguntas descritivas (afim de analisar renda, gênero e idade), comportamentais (análise de comportamento social e pessoal) e preferenciais (com intuito de saber opiniões das pessoas). Foram aplicados dois questionários, o primeiro para 182 pessoas. O resultado do questionário encontra-se na figura 5. 
Victoria, Isabel Cristina Moreira; Figueiredo, Atillio Bolivar Ourives de; Ourives, Eliete Auxiliadora Assunção; Figueiredo, Luiz Fernando Gonçalves de; Ribeiro, Giovana de Freitas Rabelo \&

Francisco Gómez Catro

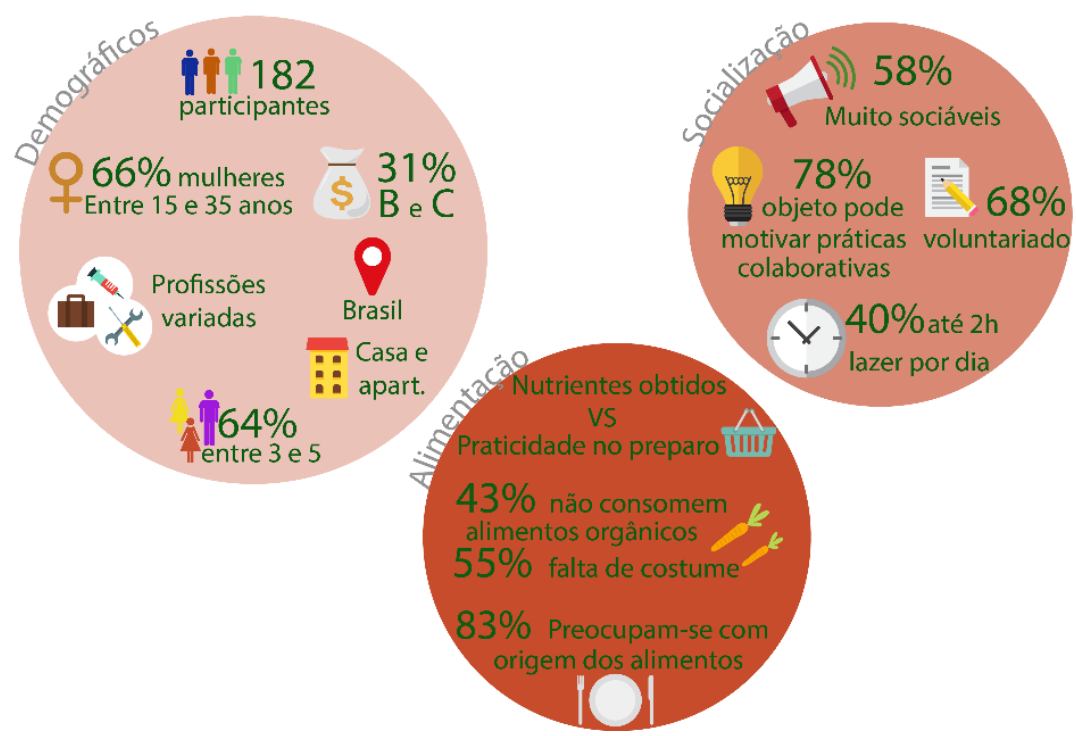

Fig. 5 Resultado do questionário.

Para realização da entrevista os métodos sugerem que as entrevistas sejam feitas com pessoas divergentes entre elas, afim de proporcionar uma visão ampla da situação. Dessa forma, foram escolhidas três pessoas para participação da entrevista. Foram feitas 8 perguntas para cada entrevistado. A síntese das entrevistas encontram-se na figura 6.

\section{Síntese entrevistas}

\section{Atividades ao ar livre perto de casa}

\section{Procuram áreas verdes para desestressar}

Possuem algum meio de transporte

Já tiveram alguma experiência de socialização nessas áreas

Estão dispostos a manutenção de um produto voltado à comunidade

Alimentação saudável é mais fácil quando praticada em grupo

Conhecem pouco o movimento Slow Food

Possuem interesse no movimento, desde que de forma natural

Fig. 6 Sintese das entrevistas. 
A observação é utilizada para observar como as pessoas agem dentro de um contexto real, sem interferir em suas atividades. Nessa técnica pode-se observar o que realmente o usuário faz, e não o que ele diz que faz. Para esse projeto a observação foi realizada em parques e praças que atendem um grande número de pessoas de diferentes comunidades. A síntese da observação se encontra na figura 7 .

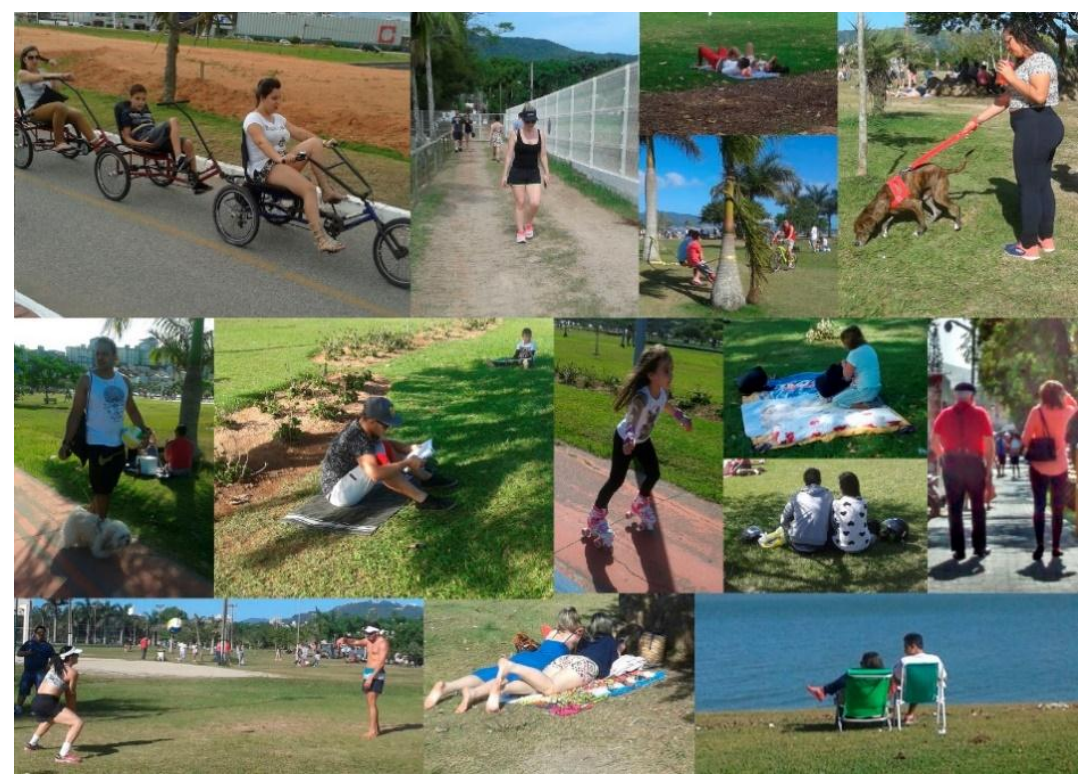

Fig. 7 Sintese da observação.

\subsection{Criar + Agir $=$ Segunda etapa}

Para a segunda etapa do projeto foram integradas ferramentas da segunda etapa do Guia NAS-Design (Agir) com as da segunda etapa do Guia de ferramentas HCD (Criar). Tanto o HCD quanto o Guia NAS-Design funcionam, nessa etapa, de forma a sintetizar todas as informações recolhidas até o momento.

Nessa etapa foram realizados os requisitos de projeto, que consistem em uma lista de necessidades que o produto deve cumprir, baseada nas análises e pesquisas realizadas durante o processo do projeto. Para melhor organização dos requisitos eles foram divididos em três grupos: requisitos de produto, usuário e contexto de uso.

Requisitos de produto consiste nas exigências referentes à forma, processos fabris, materiais e texturas do objeto: 
- $\quad$ O material deverá estar de acordo com os princípios da sustentabilidade. Bem como deverá transmitir essa preocupação ao usuário.

- Utilizar as cores próprias dos materiais utilizados para confecção do produto.

Requisitos de contexto de uso referem-se necessidades entendidas a partir do tipo de ambiente em que o produto estará, e de como ele será usado:

- $\quad$ O produto deve ser resistente, pois será criado para uso outdoor, então deve resistir a intempéries e condições climáticas desfavoráveis.

- Deve integrar as funções de socialização, práticas colaborativas e incentivo à alimentação limpa (sem elementos sintéticos e sem produtos tóxicos da indústria química) e boa (valorizar alimentos da estação, valorizar alimentos bons para saúde, trazer sensação prazerosa relacionada à alimentação saudável).

- $\quad$ Promover possibilidade de inovação social.

Requisitos de usuário consiste nas necessidades do usuário observadas durante o processo de pesquisa:

- Design clean (limpo), que não "polua" com muitas informações o lugar em que está inserido.

- $\quad$ Fácil manuseio, que possibilite uma abordagem prática do usuário.

- $\quad$ Terapêutico, um objeto em que o usuário, ao usar, possa desestressar, encontrando tranquilidade ao usá-lo.

- $\quad$ Aconchegante, sendo um porto de conforto ao usuário.

- Deve ser um produto seguro, promovendo cuidado e proteção para com os usuários.

- Integrar elementos vivos ao projeto, como temperos e pequenos vegetais, como fins terapêuticos (trazendo tranquilidade ao usuário) e aguçando os sentidos tato (contato com a planta), paladar (possibilidade de colher e comer), olfato (exalando o perfume das plantas) e visão (explorando cores e formatos dos alimentos), tudo promovendo o incentivo ao Slow food.

\subsection{Realizar + Implementar $=$ Terceira etapa}

$\mathrm{Na}$ terceira etapa do projeto foram utilizadas as últimas etapas do Guia NAS-Design (Realizar) e do kit de ferramentas do HCD (Implementar). 
Tanto no HCD quanto no Guia NAS-Design essa fase marca o início da implementação de soluções para o projeto. Nessa etapa o projeto é finalizado e define-se materiais e processos do produto.

Para definição do produto realizou-se algunas alternativas e, por fim, foi escolhida a alternativa que melhor cumpria os requisitos de projeto do produto. O produto caracterizase por ser um banco modular, o que oportuniza a integração e descontração social no

\subsubsection{Produto final}

Para definição do produto realizou-se algunas alternativas e, por fim, foi escolhida a alternativa que melhor cumpria os requisitos de projeto do produto. A alternativa final consiste em dois produtos que se complementam, formando um conjunto. O conjunto caracteriza-se por ser um banco (figura 8) e um encaixe para o banco (figura 9) para inserir plantas. O conjunto é modular, permitindo que o usuário interaja com o produto e também oportuniza a integração e descontração social no ambiente em que é inserido.

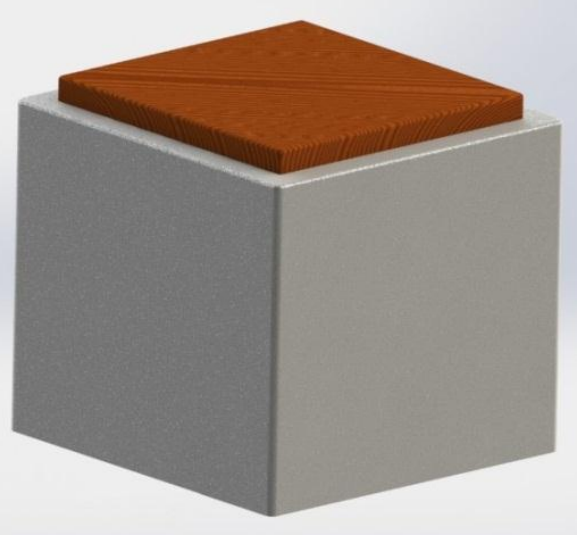

Fig. 8 Banco (2017) 
Victoria, Isabel Cristina Moreira; Figueiredo, Atillio Bolivar Ourives de; Ourives, Eliete Auxiliadora Assunção; Figueiredo, Luiz Fernando Gonçalves de; Ribeiro, Giovana de Freitas Rabelo \&

Francisco Gómez Catro

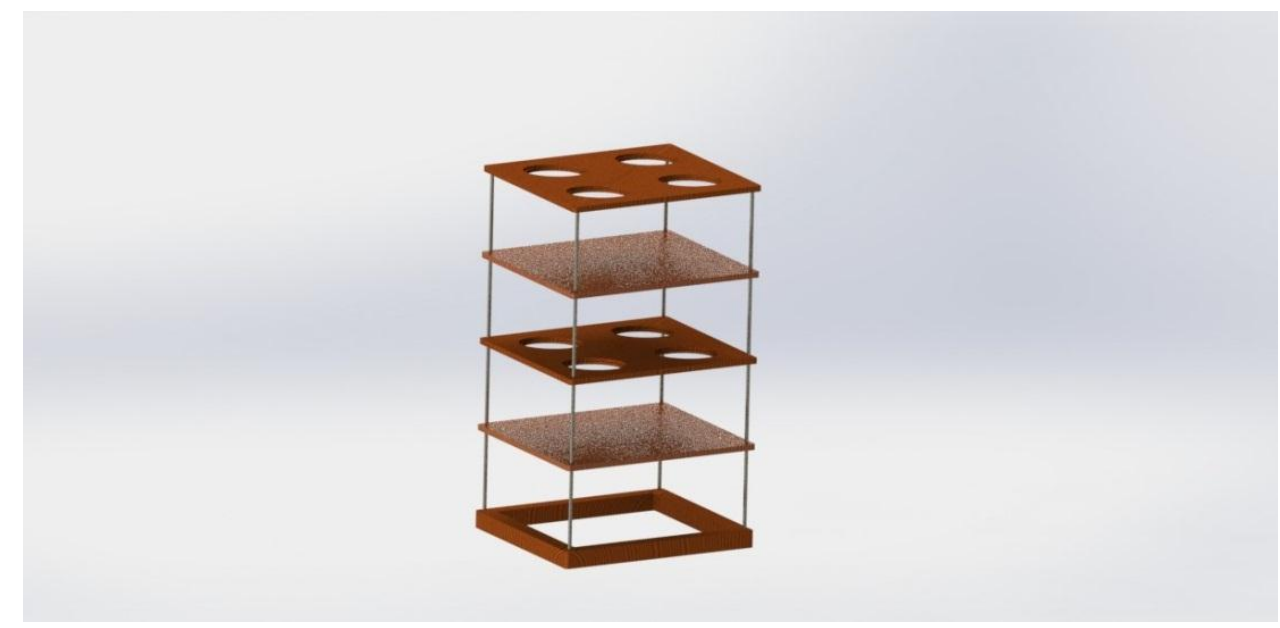

Fig. 9 Encaixe para banco (2017)

O banco tem assento removível (figura 10). O fato de o banco ter o assento removível possibilita que, se for de vontade do usuário, ele vire um vaso de plantas. Dessa forma dentro da modularidade pode estar também o vaso de planta (figura 11).

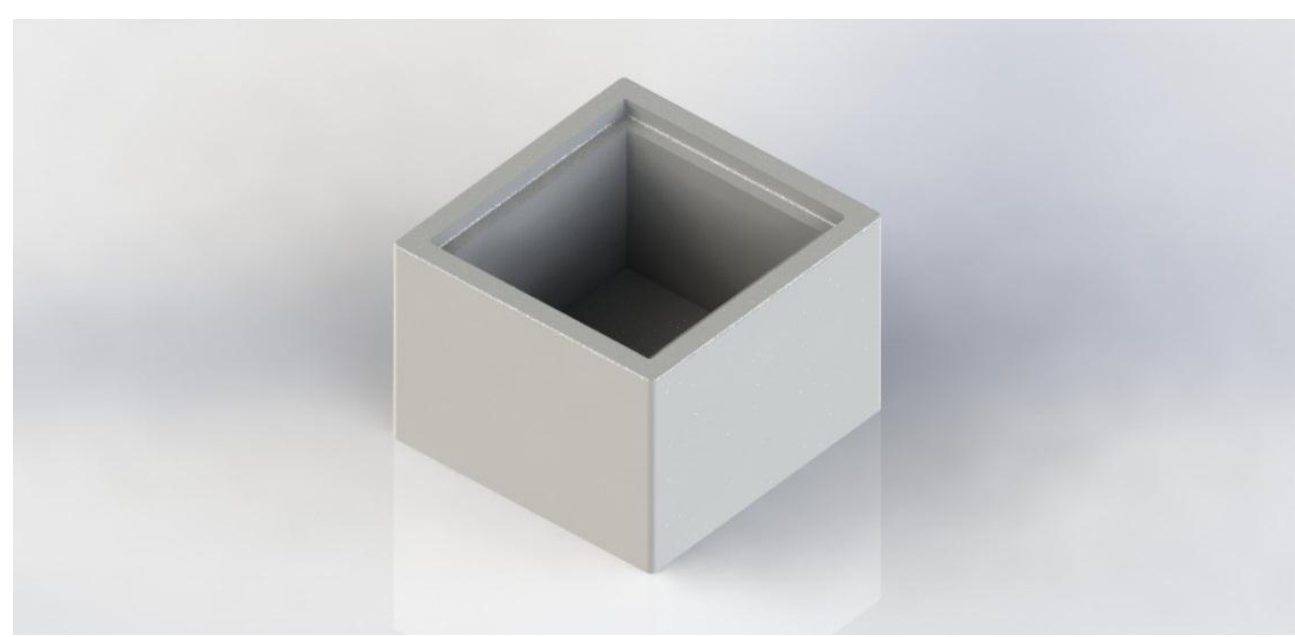

Fig. 10 Banco sem assento (2017) 


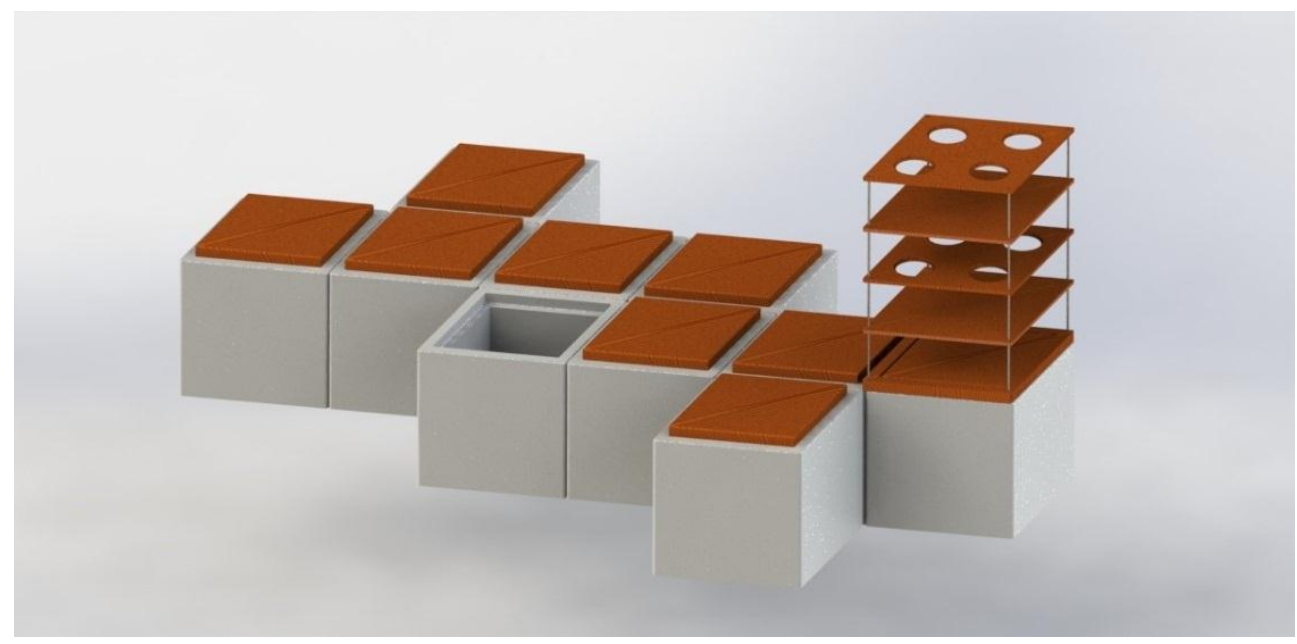

Fig. 11 Modularidade com bancos, encaixes e vaso de planta (2017)

O encaixe para o banco caracteriza-se por ser um apoiador para horta vertical. A intenção com o produto é que os usuários insiram garrafas pet nos encaixes em círculo (figura 12), posibilitando uma maior aproximação com a alimentação saudável, com o movimiento slow food e com as práticas colaborativas. Espera-se que o usuário faça um rodízio de plantas no local, em que leva para sua casa as que tem interesse e também traga outras para que as outras pessoas da comunidade desfrutem do produto. 


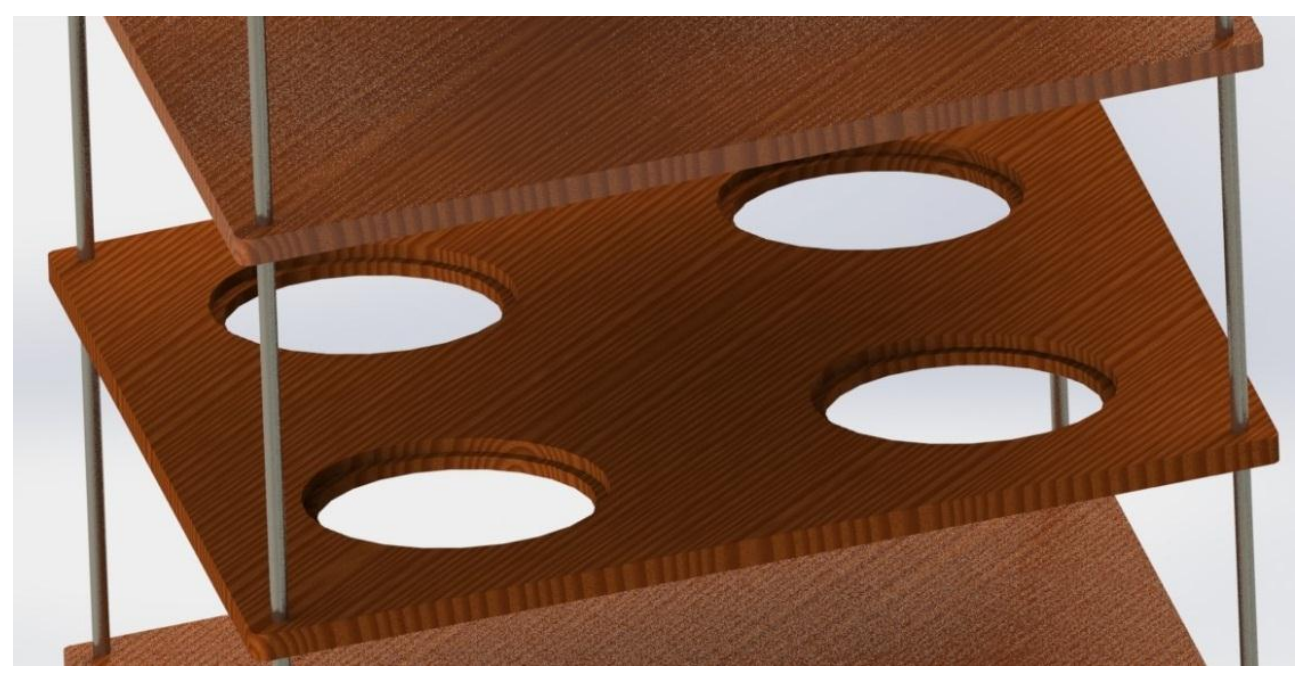

Fig. 12 Detalhe para encaixe de garrafa pet (2017)

\subsubsection{Materiais}

Para o banco o material utilizado será plástico reciclável, para conceber as questões de reciclagem tão necessárias atualmente. O plástico é, hoje, o material que o Brasil menos recicla (Landim, 2015), entretanto é um material leve e resistente, sendo ideal para projetos de design.

Para o assento e encaixe o material debe ser madeira de reflorestamento, pois não existe devastamento de mata nativa. Essas madeiras são obtidas de florestas plantadas, ou seja, esas árvores já foram plantadas com a finalidade de serem extraídas.

Para os encaixes foram escolhidas as garrafas pets para complementar o material, já que no Brasil $40 \%$ das garrafas pets ainda não são recicladas. $O$ fato de serem garrafas pets também possibilita o usuário a levar e trazer as garrafas, criando um ciclo de plantas no plantador.

\section{Considerações finais}

Partindo das tendências de comportamento da sociedade, em que as pessoas serão mais participativas, solidárias e colaborativas dentro das comunidades faz-se urgente o design agir como facilitador destas tendências, ativando o interesse da sociedade por atuar em sua comunidade, ter integração social e ser um membro ativo da comunidade. Partindo também da tendência de as pessoas serem mais atentos ao próprio bem-estar e a uma saudável forma 
de alimentação faz-se necessário a criação de productos que incentivem e apoiem essa tendência. Se todas esas tendencias forem unidas em productos disponíveis nas ruas para as pessoas, como os mobiliários urbanos, teremos comunidades com participação efetiva das pessoas, montando-se um espaço que valoriza os costumes da comunidade, gera socialização, integração no local e incentivo à alimentação saudável.

Tratar as comunidades como foco na inovação social é essencial para um bem-estar social e ambiental, já que o social faz com que o ambiental seja corretamente preservado e transmitido a gerações futuras, além de que se as comunidades se sentem parte da inovação elas tendem a ter mais autonomia e iniciativa para resolver as questões sociais colocadas na sociedade. Os parques, terrenos e praças das comunidades e outros espaços públicos em são os locais que podem iniciar essas comunidades criativas que geram inovação social, pois são espaços públicos e abertos para todos que sentirem vontade de participar ativamente da comunidade. Essa pode ser a grande oportunidade para o design nestes locais: possibilitar, por meio de artefatos, a cooperação entre indivíduos, bem como trazer a prática de uma saudável forma de alimentação.

Esse projeto buscou atender a população do Brasil, mas existe a possibilidade de ser replicado em outros países, com alterações próprias de cada cultura, incentivando também pessoas de outros lugares a prática de atividades colaborativas e troca de conhecimento, que é o caso das plantações nas garrafas pet e também a integração e inovação na sociedade, possibilitada pela modularidade dos objetos, permitindo a ampliação e compartilhamento da criatividade das pessoas.

\section{Referências}

Aros, K. (2016). Elicitação do processo projetual do Núcleo de Abordagem Sistêmica do Design da Universidade Federal de Santa Catarina. (Tese de mestrado, Universidade Federal de Santa Catarina). Recuperado de https://repositorio.ufsc.br/xmlui/bitstream/handle/123456789/167708/339441.pdf?sequence $=1 \&$ isAllowed $=\mathrm{y}$

Barbosa Filho, A. N. (2009). Projeto e Desenvolvimento de Produtos. São Paulo: Editora Atlas S.A.

Capello, G. (2008). Slow Life: vida mais calma, lenta e confortável. Recuperado de http://planetasustentavel.abril.com.br/blog/gaiatos-e-gaianos/109647/

Gogo, R. (2016). Tendências Globais de Consumo. Recuperado de http://www.aberje.com.br/blogs/post/tendencias-globais-de-consumo-para-2016

Guia Projetual NAS DESIGN (2016). Recuperado de: http://nasdesign.herokuapp.com/

IDEO (2010). HCD: Human Centered Design - kit de ferramentas. 2. ed. 
Victoria, Isabel Cristina Moreira; Figueiredo, Atillio Bolivar Ourives de; Ourives, Eliete Auxiliadora Assunção; Figueiredo, Luiz Fernando Gonçalves de; Ribeiro, Giovana de Freitas Rabelo \&

Francisco Gómez Catro

Landim, A. P. M. (2015). Sustentabilidade quanto às embalagens de alimentos no Brasil. Recuperado em: http://www.scielo.br/pdf/po/2016nahead/0104-1428-po-0101-14281897.pdf

Manzini, E. (2008). Design para a inovação social e sustentabilidade: Comunidades criativas, organizações colaborativas e novas redes projetuais. Rio de Janeiro: E-pappers.

Manzini, E. (2014). Making Things Happen: Social Innovation and Design. Design Issues.

Manzini, E. (2015). Design, when everbody designs: an introduction to design for social innovattion. Cambridge: MIT Press Book.

Slow Food Brasil (2013). Recuperado em: http://www.slowfoodbrasil.com

Thackara, J. (2008). Plano B: o design e as alternativas viáveis em um mundo complexo. São Paulo: Saraiva. 